Bryn Mawr College

Scholarship, Research, and Creative Work at Bryn Mawr College

Graduate School of Social Work and Social

Graduate School of Social Work and Social

Research Faculty Research and Scholarship

Research

2000

\title{
A Multilevel Model of Client Participation in Intensive Family Preservation Services
}

Julia H. Littell

Bryn Mawr College, jlittell@brynmawr.edu

E. A. Tajima

Let us know how access to this document benefits you.

Follow this and additional works at: http://repository.brynmawr.edu/gsswsr_pubs

Part of the Social Work Commons

\section{Custom Citation}

Littell, Julia H., and Emiko A. Tajima. "A Multilevel Model of Client Participation in Intensive Family Preservation Services." Social Service Review 74 (2000): 405-435.

This paper is posted at Scholarship, Research, and Creative Work at Bryn Mawr College. http://repository.brynmawr.edu/gsswsr_pubs/1

For more information, please contact repository@brynmawr.edu. 


\title{
A Multilevel Model of Client Participation in Intensive Family Preservation Services
}

\author{
Julia H. Littell \\ Bryn Mawr College \\ Emiko A. Tajima \\ University of Washington
}

\begin{abstract}
We identify two distinct components of parent participation in intensive family preservation services: collaboration in treatment planning and compliance with program expectations. Using hierarchical linear models, we explore influences on collaboration and compliance at the case, worker, and program levels. Effects of cross-level interactions are also examined. Parental substance abuse, mental health problems, minority status, and lack of extended family support predict lower levels of participation. Workers' perceptions of their clients and of their own working conditions appear to influence client participation. Program factors matter as well, although some operate in tandem with case characteristics and worker perceptions.
\end{abstract}

Client participation is crucial for the success of "people-changing" programs. Across diverse interventions, measures of some aspects of client participation (such as attendance, collaboration, compliance, cooperation, or role engagement) are predictive of some outcomes. ${ }^{1}$ The removal of children from their homes, one of the most important outcomes in child welfare, has been linked to parental participation. In cases of child abuse and neglect, parental cooperation with child protective services investigations reduces the likelihood of court referrals (Karski 1999). In addition, parental compliance with court-ordered assessments or treatments reduces the chance that parents will lose custody of their children (Jellinek et al. 1992; Atkinson and Butler 1996). 
Some parents and other primary caregivers of abused or neglected children are compelled to participate in intensive family preservation services (FPS). These short-term, home-based interventions are designed to change parenting behavior and improve family living conditions in order to reduce the risk of further harm to children and to avert out-ofhome placement. Parent participation in these programs is necessaryalbeit insufficient - to achieve such goals. There is some evidence that greater parental involvement in treatment planning is related to better compliance in FPS, which in turn reduces the risk of subsequent reports of child maltreatment and out-of-home placements (Littell 1999). ${ }^{2}$ Thus, whatever success FPS have may at least partly hinge on their ability to engage involuntary clients in intensive, home-based treatment-a difficult task indeed.

Most studies treat participation as a product of client characteristics (Moore-Kirkland 1981; Gitterman 1983; Miller 1985; Walitzer, Dermen, and Connors 1999). To our knowledge, no studies examine multilevel (client, worker, and program) influences on treatment participation or effects of cross-level interactions. To date, there have been no empirical investigations of factors associated with variations in client participation in FPS. Here, we explore the influence of a variety of case, worker, and program characteristics. We use these variables-and interactions among them - to explain two distinct components of participation in FPS: collaboration in treatment planning and compliance with program expectations. Although our study is of FPS, we draw on research in other settings and indulge in some speculation about the broader implications of our work.

\section{Background}

Intensive FPS were developed in the 1970s and fostered by the Adoption Assistance and Child Welfare Act of 1980 (PL 96-272), which required states to make "reasonable efforts" to prevent the out-of-home placement of children. In the late 1980s and early 1990s, most states instituted family preservation programs. Federal funds for FPS became available under the Omnibus Budget Reconciliation Act of 1993 (PL 103-66) and the Adoption and Safe Families Act of 1997 (PL 105-89). Provided in families' homes and communities, FPS include parent education, counseling, assistance with household chores, material aid, referrals to other community resources, and advocacy (Child Welfare League of America 1989; Kinney, Haapala, and Booth 1991). Most FPS programs are shortterm ( 1 to 4 months) and intense, involving up to 15 hours of face-toface contact between workers and clients per week (National Evaluation of Family Preservation Services 1995; Fraser, Nelson, and Rivard 1997). And although FPS are often described as family based, intervention tends to focus on the children's primary caregiver, usually their mother. 
Referrals to FPS are usually made by staff of public child welfare agencies, following the investigation and substantiation of reports of child abuse or neglect. Child welfare investigations take place without the consent of the parent or primary caregiver, thereby establishing the involuntary nature of FPS and other child welfare services (Budde 1990). In some cases, the courts have ordered parents to participate in FPS and even to meet specific service objectives within these programs. Thus, clients typically enter family preservation programs under coercive circumstances, including the threat (real or perceived) of child removal as a consequence of nonparticipation.

To reduce the risk of further harm to children in their own homes, parents must engage in a process of change, whether this involves altering their parenting behavior, living conditions, or both. To engage parents in FPS, workers are urged to "treat clients as colleagues" and develop collaborative relationships with them (Fraser, Pecora, and Haapala 1991; Kinney et al. 1991). At the beginning, case-specific treatment plans and objectives are usually developed to tailor the intervention to the particular needs of a family. The client's willingness and the clinician's ability to establish an agreed-on set of relevant goals are central in FPS (Schwartz, AuClaire, and Harris 1991; Cimmarusti 1992). Yet, collaboration with involuntary clients can be difficult. Parents and FPS workers often have divergent views of the nature of family problems and the proper courses of action. As in other work with involuntary clients, treatment plans may include a mixture of objectives identified by the client along with some items (related to child protection issues) that are not negotiable (Murdach 1980; Cingolani 1984; Rooney 1992).

The treatment-planning process often establishes the tenor and direction of future client-worker interactions. Client involvement in this process is thought to increase the perceived relevance of the intervention and to generate greater client commitment to the goals and tasks of treatment (Cimmarusti 1992; Littell 1999). However, there is little empirical information on the extent to which this kind of collaboration actually occurs in FPS. In Illinois, where our study was conducted, there was considerable variation in the extent of client involvement in treatment planning and agreement with treatment plans (Schuerman, Rzepnicki, and Littell 1994).

In addition to collaboration in treatment planning, client participation in FPS involves compliance with program expectations. These expectations include keeping scheduled appointments with workers, completing assigned tasks, and cooperating with workers in implementing treatment plans. Depending on the nature of family problems, the tasks assigned to FPS clients may relate to the care and supervision of children, the use of safe disciplinary measures, the performance of certain household chores or repairs, or contacts with other service providers. Some of the practical barriers to keeping appointments in agency-based services 
(e.g., transportation and scheduling problems) are resolved by the home-based design of FPS. ${ }^{3}$ But FPS clients are by no means a captive audience; some are absent when workers arrive or refuse to let them enter the home. FPS workers report that some caregivers "are openly hostile, others appear cooperative while avoiding tasks, some show great interest in the [material] benefits of the program . . . but not the child protection issues, and some exhibit considerable motivation" to change (Budde 1990, pp. 15-16). Clients' exposure to FPS intervention is moderated by the extent to which they keep appointments, complete assigned tasks, and cooperate with FPS workers. In Illinois, there was considerable variation on measures of these three aspects of compliance (Schuerman et al. 1994), and these variations were predictive of certain outcomes (Littell 1999).

\section{Conceptual Framework}

Although most explanations for variations in treatment participation have centered on client variables (Moore-Kirkland 1981; Gitterman 1983; Miller 1985; Walitzer et al. 1999), we view participation as a function of multiple influences, including those at the case, worker, and program levels (see fig. 1). In this view, participation is a goal and intermediate outcome of intervention, not an immutable product of client characteristics. Here we focus on predictors of collaboration and compliance in FPS. The model we tested is represented by the dark arrow in figure 1 .

We examine the effects on participation of case characteristics, but these are primarily viewed as control variables. We are more interested

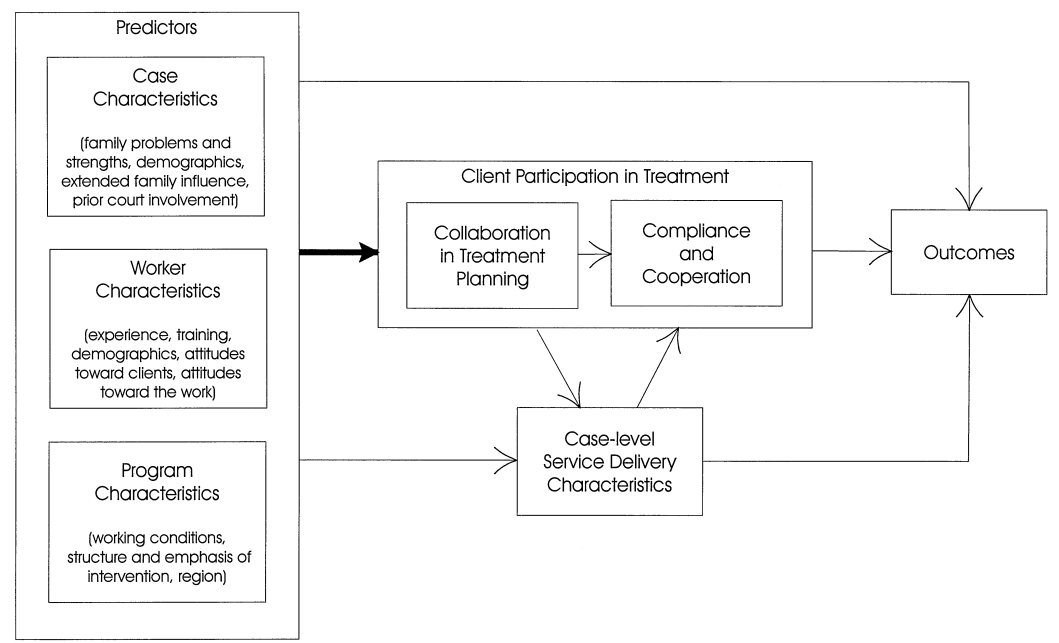

FIG. 1.-A model of client participation in family preservation services 
in worker and program effects, since these have been underinvestigated. We examine the direct effects of worker characteristics on client participation along with the effects of interactions between worker and client variables. We expect program characteristics to have both direct and indirect effects by providing conditions that facilitate or impede client participation and by enhancing or hindering workers' efforts.

\section{Case-Level Predictors}

The presence of chronic or severe parent and family problems, especially those that impair caregiver functioning, may predict initial difficulties in treatment participation. There is evidence that parental substance abuse is related to noncompliance with court-ordered assessments and treatment in cases of child abuse and neglect (Famularo et al. 1989; Murphy et al. 1991; Butler, Radia, and Magnatta 1994). Cases of chronic child neglect are thought to be particularly difficult to engage in FPS because many of these families have long-standing problems in multiple areas (Berry 1993). The presence of parental mental health problems, severe child-care skill deficits, and inadequate housing pose special challenges for FPS workers (Littell and Schuerman, in press). Therefore, we expect to find lower levels of participation in FPS among caregivers with any of these presenting problems.

Early childbearing and minority group status are among the background characteristics associated with low rates of participation in outpatient mental health services (Kazdin, Holland, and Crowley 1997). These are "variables of convenience" that are easily obtained and encompass broad characteristics "that neither shed light on the possible mechanisms involved in [participation] nor suggest guidelines for where, when, and how to intervene" (Kazdin et al. 1997, p. 453). We include measures of parental age and race in our study to control for variations in these factors.

Family cohesion and the influence of significant others have been linked to variations in compliance in health care (Blackwell 1997) and to continuation in outpatient mental health services (Armbruster and Fallon 1994; Kazdin et al. 1997). Family conflict over involvement in FPS may impede caregiver participation, while family support is likely to enhance it.

The influence of court orders on treatment participation has been the subject of several other studies in child welfare (e.g., Wolfe et al. 1980; Irueste-Montes and Montes 1988; Famularo et al. 1989), but results are not consistent across studies. It seems that a reciprocal relationship may exist between court involvement and treatment participation. Hoping that the "long arm of the law" will enhance participation, some FPS workers seek court orders in cases of parental noncompliance. In this study we examine the influence on participation of court involvement prior to the referral to FPS. 
Case-level variations in treatment participation are also likely to be affected by the amounts and types of services provided. For example, clients who are actively involved in treatment planning may request (and receive) more material aid, and the receipt of tangible benefits may increase their willingness to participate in FPS. For reasons discussed below, we did not examine relationships between case-level service delivery characteristics and participation, but this is an important topic for another study.

\section{Worker-Level Predictors}

Caseworkers who work with families of abused and neglected children in their homes and communities require a high level of stamina and skill. Successful caseworkers must be responsive to individual needs and unexpected problems, able to form personal relationships with parents and other family members, and tenacious in advocating for clients in other service systems and bureaucracies (Glisson and Hemmelgarn 1998, p. 404; also see Halpern 1997). We expect worker background characteristics (e.g., education and experience), views of clients, and attitudes toward their work to affect job performance, which in turn may affect client participation.

Caseworkers' education and training are thought to influence both their style and effectiveness (Pecora, Fraser, and Haapala 1991), although it is not clear whether FPS workers with advanced degrees are more effective than others (Fraser, Pecora, and Lewis 1991). Workers with advanced training may possess greater knowledge and skills, but professionalism and higher socioeconomic status may increase their social distance from clients (Soulé, Massarene, and Abate 1993). We consider how parent participation is affected by workers' race, education, and professional experience in three fields (child welfare, individual and family therapy, and home-based services). These background variables may be directly related to participation or may interact with case characteristics, that is, some workers may be more effective in engaging certain kinds of clients.

FPS workers' beliefs about the nature and etiology of family problems have some bearing on their casework activities, which in turn are related to clients' responses to treatment (Kim 1993). Hye Lan Kim (1993) identified two general orientations held by FPS workers: a psychological orientation, in which emphasis is placed on intrapersonal and interpersonal problems, and a sociological orientation, in which child maltreatment is viewed as a function of poverty, discrimination, and other extrafamilial factors. Akin to concerns about "parent blaming" in mental health, we posit that workers who tend to focus on clients' personal deficits will be less effective than others in engaging parents in FPS.

Workers' attitudes toward their work are thought to affect the quality of services provided to clients (Kirk, Koeske, and Koeske 1993), which 
may affect client participation. Although child welfare workers have reported moderate to high levels of job satisfaction, their work environments are characterized by considerable role ambiguity and stress (Jayaratne and Chess 1984). In relation to job stress, much attention has been paid to the phenomenon of worker burnout-a cluster of symptoms including emotional exhaustion, low sense of accomplishment, and the depersonalization of clients (Drake and Yadama 1996). Just as problems that impair client functioning may serve as impediments to participation in FPS, burnout is likely to compromise the worker's ability to engage parents and encourage participation. Other factors likely to affect job performance include workers' senses of job clarity (vs. role ambiguity; see Jayaratne and Chess 1984; Stott and Musick 1994), autonomy (Lipsky 1980), and the quality of supervision (Halpern 1997; Um and Harrison 1998). We expect that greater role clarity, autonomy, and perceived support from supervisors facilitate home-based work with child welfare clients.

Considerable differences exist between FPS workers regarding the extent to which they involve clients in treatment planning. In Illinois, formal treatment plans were viewed by some workers as an important part of the casework process, while others saw this as a paperwork chore or a meaningless bureaucratic requirement "separate from the most important elements of intervention" (Rzepnicki and Budde 1991, p. 124). Although most FPS workers thought that involving clients in service planning was extremely important, case objectives were often based on problems identified by the worker (Schuerman et al. 1994). Some workers took the lead in setting goals and developing treatment plans because they believed it was helpful to provide structure and direction for families (Littell and Howard 1990) or because they thought that child protection concerns outweighed parents' interests. In this study, we expect worker-level differences in collaboration, but we do not attempt to identify all of the reasons for this variation.

\section{Program-Level Predictors}

Although "good practice with multiply vulnerable families requires support for frontline providers themselves" (Halpern 1997, p. 266; see also Stott and Musick 1994), little is known about the program structures and supervisory supports needed to promote effective FPS (Pecora et al. 1991). Organizational structures can "provide the detailed guidance and emotional support that sustain day-in, day-out work. Yet attending to the internal structure of human service programs . . . is one of the most overlooked essentials of good services. It is especially critical in helping frontline providers and supervisory staff recognize and work to neutralize (to the extent possible) the stresses attendant to . . . working with multiply vulnerable families" (Halpern 1997, p. 268).

Over the past 50 years, extensive research in business and industrial 
organizations has shown that employees' shared attitudes about their work - the organizational climate-are important predictors of organizational effectiveness (Glisson and Hemmelgarn 1998). Although there has been relatively little research on this topic in human service organizations, Charles Glisson and Anthony Hemmelgarn (1998) showed that positive organizational climate predicted better quality services and more positive outcomes in children's services. Because they operate in highly stressful situations, the "climate of their work environments should be powerful determinants of how caseworkers respond to unexpected problems, the tenacity with which difficult problems are solved, and the affective tone of their work-related interactions with children and families" (Glisson and Hemmelgarn 1998, p. 404). Positive climates may complement and encourage the type of casework activities that enhance client participation. On the other hand, heavy workloads and negative climates may interact with worker characteristics to create workrelated stressors that can result in burnout (Cherniss 1980; cited in Um and Harrison 1998). We expect organizational climate to affect client participation indirectly, through its impact on workers and their job performance.

There was considerable variation among the FPS programs in our study in terms of the structure and emphasis of services. Small caseloads, intense client contact, and an emphasis on providing material aid, clinical services, and case-level advocacy efforts are thought to be important elements of FPS (Fraser, Pecora, and Haapala 1991; Kinney et al. 1991; Pecora et al. 1991) and may affect client participation.

Finally, we explore the differences between programs in a large urban area (Chicago) and those in the remainder of the state. The urban area poses special challenges for clients and workers that may affect collaboration and compliance (e.g., physical dangers and problems associated with the size and bureaucratic nature of local service organizations).

\section{Research Design}

Our analysis is based on data gathered during a large-scale evaluation of FPS in Illinois. Family preservation services were provided by 64 private agencies under contracts with the Illinois Department of Children and Family Services (DCFS). Although DCFS set guidelines regarding the duration, intensity, and types of services to be provided in these programs, the private agencies had latitude to develop FPS programs that reflected their own experience, philosophy, clientele, and community needs. This led to many variations in structure and emphasis across programs. Family preservation services were usually provided over a 3-month period and included some mixture of clinical interventions and material aid (Schuerman et al. 1994). On average, families had 5-6 hours of in-person contact with FPS workers per week, but this varied 
across sites (Schuerman et al. 1994). Most contacts occurred in the family's home and, to a lesser extent, en route to other agencies.

Families with substantiated reports of child abuse or neglect were referred to FPS programs by DCFS workers. Initial eligibility criteria included the stipulation that at least one child in the family was at "imminent risk" of out-of-home placement, but few FPS cases actually met this criterion (Schuerman et al. 1994). Informally, referral criteria shifted, and families who were thought to need further assessment or assistance were sent to FPS (Littell et al. 1993). Most of the families in our sample had young children (56 percent had at least one child under 2 years old), 43 percent were headed by single adults, and 40 percent of the primary caregivers were African American. Family problems identified by workers included parental mental health problems (in 37 percent of the cases), severe child-care skill deficits (42 percent), inadequate or dangerous housing (27 percent), and substance abuse (36 percent). Cases of sexual abuse in which the perpetrator was still in the home were not eligible for FPS; few cases of sexual abuse were referred.

The evaluation of the Illinois FPS programs was conducted by the Chapin Hall Center for Children at the University of Chicago, under contract with DCFS (see Schuerman et al. 1994). Data on family preservation clients, caseworkers, agencies, services, and outcomes were collected from 1989 to 1993. Information on family and service characteristics was obtained on a 12-page service summary form, which was completed by the FPS caseworker approximately 90 days after the family's referral. Additional case information was retrieved from state administrative records.

For purposes of this analysis, we excluded cases served in the first year (1989), when the FPS program had not been fully implemented, and those that entered the program after March 1991, when data collection efforts began to concentrate on selected experimental sites. Our sample is the cohort of all $(2,681)$ families who entered family preservation programs in Illinois over a 15-month period from January 1, 1990, through March 31, 1991. Valid data on all case-level measures in our analysis are available for 2,246 (84 percent) of these families. Cases without valid data were dropped from further analysis.

The families in our study were served by 334 private agency caseworkers. Data on worker demographics and prior work experience were gathered via a self-administered survey completed by 86 percent of the workers in our sample. Most (80 percent) of these caseworkers were female, 44 percent were under age 30 , and 38 percent held master's degrees. On an annual basis, FPS workers were asked to complete another questionnaire, adapted from the Family-Based Services Inventory (Nelson, Landsman, and Hutchinson 1986) and the Maslach Burnout Inventory (Maslach and Jackson 1986), which included questions about their working conditions, program philosophy and emphasis, views of the 
kinds of families they served, and factors related to staff turnover and burnout. Two-thirds of the workers in our study responded to one or more of these annual surveys. We discuss below the methods used to handle missing data on these instruments.

In sum, our analysis includes 2,246 families served by 334 workers in 64 private social service agencies. Each worker served up to 32 cases in our sample $($ mean $=6.7$, median $=4.0)$, and there were up to 16 workers in each program (mean $=5.2$, median $=5.0$ ). The Illinois data provide a rich source of information for our purposes. Although many current FPS programs closely resemble those in Illinois in the early 1990s, our results cannot be generalized to programs in other states or even to present-day programs in Illinois.

\section{Measures}

Treatment participation.-On the service summary form, FPS caseworkers rated the extent to which the primary caregiver participated in developing a service plan, agreed with the plan, initiated contact with the agency, kept scheduled appointments, completed assigned tasks satisfactorily, and cooperated with them. These six items, rated on threepoint, ordinal scales, were submitted to maximum-likelihood factor analysis with promax rotation (see Littell 1999). Two underlying factors were revealed: two variables - participation in treatment planning and agreement with treatment plans-loaded, at .79 or higher, on the first factor, which we called "collaboration." Three variables-keeping appointments, completing tasks, and cooperation-had loadings of .64 or higher on the second factor, which we called "compliance." Contact initiation was not associated with either factor (loadings were under .4) and was dropped from further analysis. For subsequent analysis, we created two additive scales, one representing each factor, by computing the means of original variables and then converting them to $z$-scores. Both scales demonstrated acceptable internal consistency (for collaboration, Chronbach's $\alpha=.74$; for compliance, $\alpha=.86$ ). The two scales were correlated at .53. Both scales are used here but not in the same analysis.

Case-level predictors.-Predictors of collaboration and compliance include dummy variables representing the caregivers' age (teenage or older), race (African American or other), court involvement prior to referral to FPS, and FPS caseworkers' reports of the presence of parental mental health problems, severe child-care skill deficits, substance abuse, and housing problems (table 1). We also included the number of previous substantiated reports of child neglect (derived from state administrative data) and FPS workers' ratings of the influence of extended family members.

Worker characteristics. - We examined worker characteristics, including dummy variables representing race (African American or other), edu- 
Table 1

Case-Level Predictors $(N=2,246)$

\begin{tabular}{|c|c|c|c|c|c|}
\hline Variable & $\%$ & Mean & SD & $\begin{array}{l}\text { Mini- } \\
\text { mum }\end{array}$ & $\begin{array}{l}\text { Maxi- } \\
\text { mum }\end{array}$ \\
\hline Substance abuse . & 35.7 & $\ldots$ & $\ldots$ & 0 & 1 \\
\hline Parental mental health problems ........... & 36.8 & $\ldots$ & $\ldots$ & 0 & 1 \\
\hline 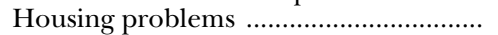 & 27.1 & $\ldots$ & $\ldots$ & 0 & 1 \\
\hline Child-care skill deficits (severe) ............. & 41.8 & $\cdots$ & $\cdots$ & 0 & 1 \\
\hline Teenage primary caregiver ………............... & 9.8 & $\ldots$ & $\ldots$ & 0 & 1 \\
\hline African-American primary caregiver .... & 40.0 & $\ldots$ & $\ldots$ & 0 & 1 \\
\hline $\begin{array}{l}\text { Chronic neglect (number of substanti- } \\
\text { ated reports of child neglect prior } \\
\text { to referral to FPS) }\end{array}$ & ton & .94 & .90 & 0 & 7 \\
\hline Prior court involvement (family court & & & & & \\
\hline hearing prior to referral to FPS) ... & 12.9 & $\ldots$ & $\ldots$ & 0 & 1 \\
\hline Extended family influence .......................... & & $\cdots$ & $\cdots$ & -1 & 1 \\
\hline$-1=$ negative influence $\ldots \ldots \ldots \ldots \ldots \ldots \ldots$ & 18.5 & $\cdots$ & $\cdots$ & $\cdots$ & $\cdots$ \\
\hline $0=$ no influence & 37.8 & $\cdots$ & $\cdots$ & $\cdots$ & .. \\
\hline 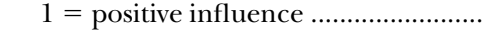 & 43.7 & $\cdots$ & $\cdots$ & $\cdots$ & $\cdots$ \\
\hline
\end{tabular}

NoTE. - FPS $=$ family preservation services; $N=$ number.

cation (master's degree or less), and prior work experience (of 1 year or more) in child welfare, in-home services, and individual or family therapy (see table 2). Based on Kim's (1993) work and our replication of her analysis in this sample, we created a "deficit orientation" scale that represents the extent of worker agreement with items indicating that their clients had "problems of their own making," skill deficits, little motivation, and few strengths. A 17-item burnout scale was adapted from the Maslach Burnout Inventory (Maslach and Jackson 1986). ${ }^{4}$

Working conditions. - On the annual surveys, workers used a four-point scale to rate the adequacy of the supervision they received. Twenty-five items were used to assess workers' views of other aspects of their working conditions, and factor analysis revealed several underlying dimensions, which we labeled job clarity, autonomy, enough time to complete the work, and positive climate. Job clarity was best represented by a single item, which was retained in its original format. Scales were created based on the original items that loaded on the factors we called autonomy (five items), enough time (four items), and positive climate (eight items). There was substantial variation between workers within programs on the perceived adequacy of supervision, job clarity, and autonomy scales; these are retained as worker-level variables (see table 2). Worker ratings of time pressure and climate were rather consistent within programs, but there were significant differences between programs on these two measures; hence, aggregate scores (program-level means) are treated as program characteristics (table 3). Measures of internal consistency are reported in tables 2 and 3 (Chronbach's $\alpha$ s are about 7 or higher). 
Table 2

Worker-Level Predictors $(N=334)$

\begin{tabular}{|c|c|c|c|c|c|}
\hline Description & $\%$ & Mean & SD & $\begin{array}{l}\text { Mini- } \\
\text { mum }\end{array}$ & $\begin{array}{l}\text { Maxi- } \\
\text { mum }\end{array}$ \\
\hline Master's degree …................ & 38.3 & $\cdots$ & $\cdots$ & 0 & 1 \\
\hline Child welfare experience & & & & & \\
\hline $\begin{array}{l}(1 \text { year }+) \\
\text { In-home services experience }\end{array}$ & 49.1 & $\cdots$ & $\cdots$ & 0 & 1 \\
\hline$(1$ year +$)$ & 63.5 & $\ldots$ & $\ldots$ & 0 & 1 \\
\hline $\begin{array}{l}\text { Individual/family therapy experience } \\
(1 \text { year }+)\end{array}$ & 24.3 & $\cdots$ & $\cdots$ & 0 & 1 \\
\hline African-American caseworker ....................... & 38.9 & $\ldots$ & $\ldots$ & 0 & 1 \\
\hline Supervision adequacy (rating) .................... & $\ldots$ & 3.13 & .63 & 1 & 4 \\
\hline Job clarity (rating) . & $\ldots$ & 3.19 & .56 & 1 & 4 \\
\hline Autonomy* ................. & .. & 0 & 1 & -4.51 & 2.51 \\
\hline Deficit orientation $^{+} \ldots$ & $\ldots$ & 0 & 1 & -3.30 & 4.01 \\
\hline 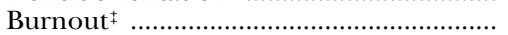 & $\ldots$ & 0 & 1 & -1.70 & 1.70 \\
\hline
\end{tabular}

NoTE. $-N=$ number.

* Scale of five items (each rated on a four-point Likert scale): "I had the freedom to decide what I did on the job," "I was given a chance to do the things I do best," "I decided the speed with which I worked," "It was my responsibility to decide how my job got done," and "I decided who I worked with on the job" (Chronbach's $\alpha=.74$ ).

+ Scale of seven items indicating agreement (on a four-point Likert scale) that most of the families: "had some problems of their own making," "were deficient in some parenting skills," "lacked motivation to change," "came from troubled families themselves," "were very disorganized," "were deficient in some housekeeping skills," and "didn't have a lot of strengths" $(\alpha=.65)$.

¥ Standard score based on the mean of 17 items adapted from Maslach and Jackson’s (1986) Burnout Inventory $(\alpha=.82)$.

Program characteristics. - Our program characteristics include average caseload size, region (Chicago or other), and aggregate measures of service delivery. For the latter, we computed the mean intensity of services (hours of in-person contact per day) across cases in a program, mean number of concrete services provided, proportion of cases in which there was (reported) advocacy work, and the proportion of cases that received individual or family counseling in FPS. There were significant differences between programs on all of these variables (table 3 ). With the exception of region, our program-level measures are not independent of worker- or case-level data. The internal consistency of these measures depends on the amount of variation within programs as well as the size of the worker and case samples within each program. Estimates of the reliability of program-level means range from .66 to .93 (see table 3 ). ${ }^{5}$

\section{Analytic Models}

\section{Preliminary Analysis}

Missing values on worker-level predictor variables were imputed using the regression method; there were no missing values on the two criterion 


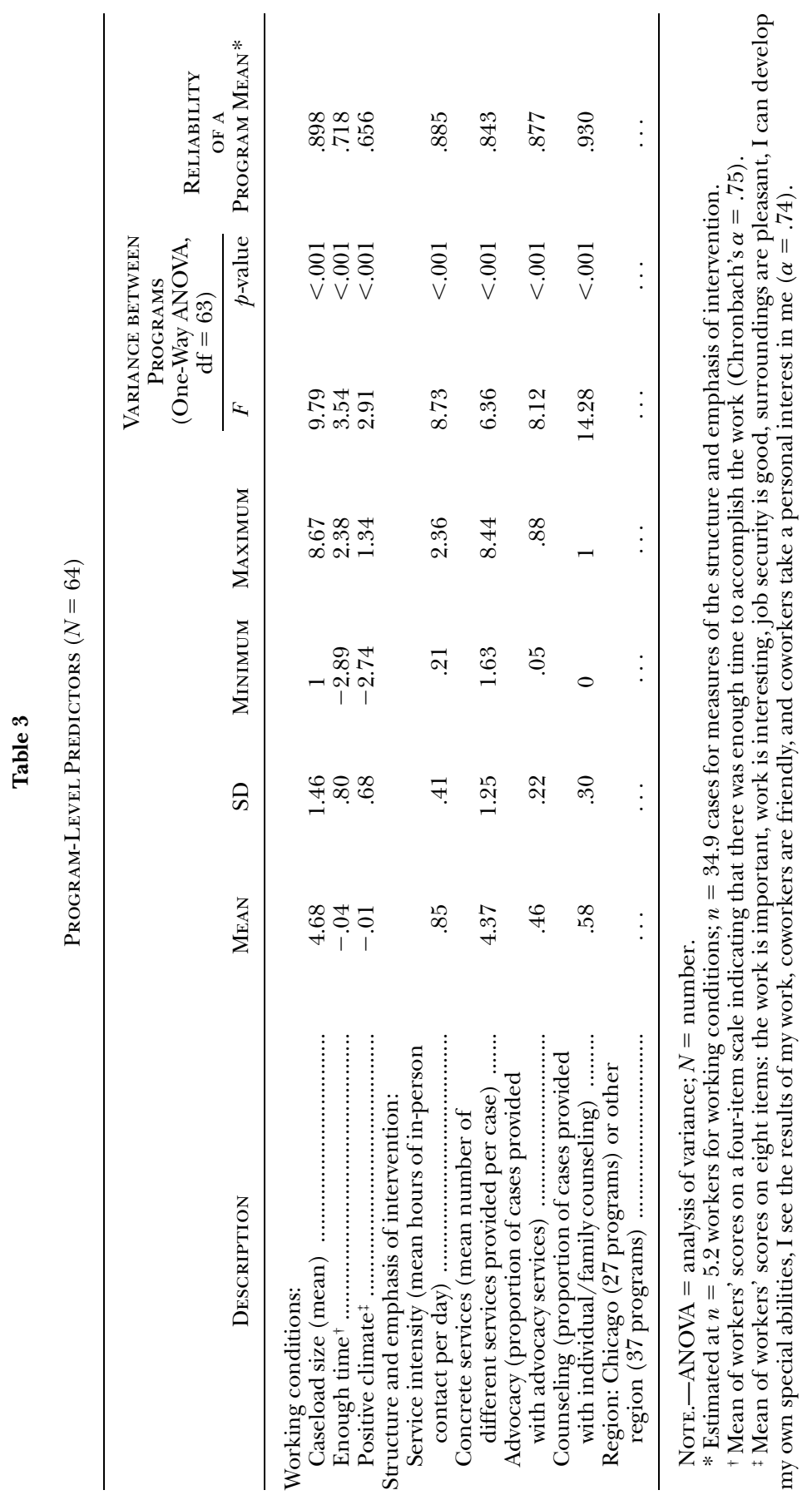


(participation) variables. To avoid multicollinearity, we selected predictor variables that had low zero-order correlations $(<|.3|)$ with all other predictors at that level. We then ran ordinary least squares regressions on each participation scale, using Huber corrections for autocorrelated observations. ${ }^{6}$ Variables that were not related to either participation scale were dropped from further analysis. Case-level characteristics that were unrelated to collaboration or compliance were the number and ages of children, single parent status, the number of prior reports of child abuse, and prior out-of-home placements. Nonsignificant worker characteristics included gender, age, and an overall rating of job satisfaction.

Some service characteristics (e.g., the number of concrete services provided) were strongly associated with collaboration and compliance, but the direction of causality in these relationships was unclear. Thus, we developed simultaneous equations, estimated with three-stage least squares, to determine whether there were reciprocal relationships between the service variables and the participation scales. There were significant effects in both directions: service characteristics affected participation, and participation affected service characteristics. Preliminary analysis also indicated that case-level measures of service delivery were related to both client and worker characteristics. Since we could not untangle these relationships in the present study, we decided to forgo analysis of the potential impact of case-level service characteristics on collaboration and compliance.

\section{Hierarchical Linear Models}

Hierarchical linear modeling (HLM) is useful for analyzing clustered observations (Bryk and Raudenbush 1992). Our observations are nested in a three-level hierarchical structure: multiple cases are served by each worker, and workers are clustered within programs. Simple HLM models provide the best estimates of the proportion of variance in criterion variables that can be attributed to each level. More complex models are used to estimate the effects of predictor variables and cross-level interactions. In this study, three-level HLM is used to estimate the effects on collaboration and compliance of (1) case characteristics, (2) worker characteristics, (3) interactions between variables at the case and worker levels, (4) program characteristics, (5) interactions between case and program variables, and (6) interactions between worker and program variables.

First, simple three-level hierarchical linear models are used to identify the proportion of variance in collaboration and compliance that lies between cases served by the same worker (level 1), between workers within each program level (level 2), and between FPS programs (level 3). At level 1 (the case level), the simplest, "fully unconditional," model is

$$
Y_{i j k}=\pi_{0 j k}+e_{i j k}
$$


where $Y_{i j k}$ is the score for case $i$ served by worker $j$ in program $k ; \pi_{0 j k}$ is the mean for worker $j k$; and $e_{i j k}$ is a level 1 random effect, the deviation of the case score from the worker mean.

At level 2, each worker mean becomes a dependent variable and is modeled as a function of $\beta_{0 k}$, the program mean, and a level 2 random effect:

$$
\pi_{0 j k}=\beta_{0 k}+r_{j k}
$$

At level 3, the program mean is a function of the grand mean, $\gamma_{0}$, and a level 3 random effect, $u_{k}$ :

$$
\beta_{0 k}=\gamma_{0}+u_{k}
$$

In combined form, the fully unconditional model is

$$
Y_{i j k}=\gamma_{0}+u_{k}+r_{j k}+e_{i j k}
$$

that is, the score for any individual case is equal to the grand mean, plus the deviation of the program mean from the grand mean, the deviation of the worker mean from the program mean, and the deviation of the case score from the worker mean.

To identify the impact of case, worker, and program characteristics on treatment participation, we add predictor variables to the models at all three levels. First, all level 1 predictors (including dummy variables) are centered around their grand means, so that the intercept, $\pi_{0 j k}$, represents the mean participation score for worker $j$ in program $k$, adjusted for differences in caseload composition. For example, approximately 10 percent of the primary caregivers in the sample are teenagers. By centering the dummy variable for teenage caregiver around its grand mean (.098), the variable now takes on one of two values: .902 ( $1-.098)$ and $-.098(0-.098)$. Grand-mean centering adjusts for differences between workers in the proportion of teenage caregivers in their caseloads. (For convenience and ease of interpretation, we also centered all level 2 and level 3 predictors around their grand means.) At each level, we limit the number of parameter estimates (to conserve statistical power) by using backward elimination of variables that are not statistically significant $($ at $p<.05)$.

The level 1 "unconditional" model is

$$
Y_{i j k}=\pi_{0 j k}+\sum_{p=1}^{P} \pi_{p j k}\left(X_{p i j k}-\bar{X}_{p} . .\right)+e_{i j k},
$$

where $X_{p i j k}$ represents the value of a level 1 predictor for case $i j k$. There are $p$ predictors, each centered around its grand mean. Expression $\pi_{p j k}$ 
is a level 1 coefficient (slope), showing the direction and strength of the relationship between the predictor and the dependent variable, $Y$, for worker $j$ in program $k$.

At the second level, we model the effects of worker characteristics on mean participation values for each worker as

$$
\pi_{0 j k}=\beta_{0 k}+\sum_{q=1}^{Q} \beta_{q k}\left(W_{q j k}-\bar{W}_{q} . .\right)+r_{j k},
$$

where $w_{q j k}$ is a worker-level predictor, centered around its grand mean, and $\beta_{q k}$ is the corresponding slope. At level 3, the model is

$$
\beta_{0 k}=\gamma_{0}+\sum_{s=1}^{s} \gamma_{\mathrm{s}}\left(A_{s k}-\bar{A}_{s} .\right)+u_{k} .
$$

Expression $\gamma_{s}$ is a level 3 slope, and $A_{s k}$ is the value of a level 3 predictor for program $k$, which is centered around its grand mean.

In combined form, the three-level unconditional model is

$$
\begin{aligned}
Y_{i j k}= & \gamma_{0}+\sum_{s=1}^{S} \gamma_{s}\left(A_{s k}-\bar{A}_{s} . .\right)+\sum_{q=1}^{Q} \beta_{q k}\left(W_{q j k}-\bar{W}_{q .} .\right) \\
& +\sum_{p=1}^{P} \pi_{p j k}\left(X_{p i j k}-\bar{X}_{p} . .\right)+u_{k}+r_{j k}+e_{i j k} .
\end{aligned}
$$

In other words, the value of participation for any given case is equal to the grand mean plus the sum of the effects of program characteristics, plus the sum of the effects of worker characteristics, plus the sum of the effects of case characteristics, plus random error (unexplained variance) at all three levels. The impact of a higher-level variable is measured as its effect on a lower-level intercept.

Thus far, we have treated intercepts (means) as outcomes and predictor variables as fixed effects. But the effects of worker and program characteristics may not be constant across cases. As indicated above, interactions between worker and client characteristics may affect collaboration and compliance, and certain organizational environments may foster participation among some kinds of clients and not others. For example, parental substance abuse is related to relatively low levels of compliance in FPS, but some workers and programs may be more effective than others in these cases. If so, the level 1 slope for substance abuse will not be constant across either workers or programs. These variations may be random or nonrandom; nonrandom variations are those that can be explained by worker or program characteristics. 
In "conditional" hierarchical linear models, slopes are treated as outcomes of one or more predictor variables at the next level. In addition to modeling sources of variation in worker and program means, we examine sources of nonrandom variation in the slopes of level 1 and level 2 predictors. First, we identify worker characteristics that relate to systematic variations in the slopes for case characteristics, although we are well aware that our data cannot capture the complexity of these interactions. When level 1 slopes are treated as outcomes,

$$
\pi_{p j k}=\beta_{p 0 k}+\sum_{q=1}^{Q p} \beta_{p q k}\left(W_{p q j k}-\bar{W}_{p q} . .\right)+r_{p q j k}
$$

where $\pi_{p j k}$ is the slope of a level 1 predictor $(p)$ for worker $j$ in program $k$, and $\beta_{p 0 k}$ is the mean value of that slope for program $k$. Similarly, $\beta_{p q k}$, a level 2 coefficient, can be expressed as a function of the grand mean of that coefficient (slope) plus the effects of level 3 predictors and random error.

To explain variations in level 1 slopes, level 2 predictors are selected using backward elimination. With level 2 predictors in the models, we add level 3 variables and eliminate those that are not significant. Using level 3 predictors, we then explore sources of nonrandom variation in the effects of level 2 variables on the dependent measures. To capture cross-level interactions, the main effects of variables that relate to lowerlevel slopes are retained (in equations of worker or program means) regardless of whether these main effects are statistically significant.

When we allow each of the slopes to vary randomly at higher levels (with predictors in the models), none of the random variations are statistically significant. Hence, we treat all slopes as fixed or nonrandomly varying (i.e., functions of higher-level variables).

The final, conditional model of collaboration is:

level 1:

collaboration $=\pi_{0}+\pi_{1}$ (substance abuse $)+\pi_{2}$ (parental mental health problems $)+\pi_{3}$ (child-care skill deficits) $+\pi_{4}$ (caregiver race $)+\pi_{5}($ extended family

level 2: influence) $+e$

$$
\begin{aligned}
\pi_{0}= & \beta_{00}+\beta_{01}(\text { worker education })+\beta_{02}(\text { child welfare } \\
& \text { experience })+\beta_{03}(\text { worker race })+\beta_{04}(\text { supervision } \\
& \text { adequacy })+\beta_{05}(\text { job clarity })+\beta_{06}(\text { deficit orienta- } \\
& \text { tion })+\beta_{07}(\text { burnout })+r_{0} \\
\pi_{1}= & \beta_{10}+\beta_{11}(\text { worker education }) \\
\pi_{3}= & \beta_{30}+\beta_{31}(\text { child welfare experience }) \\
\pi_{5}= & \beta_{50}+\beta_{51} \text { (supervision adequacy) }
\end{aligned}
$$


level 3:

$$
\begin{aligned}
\beta_{00}= & \gamma_{000}+\gamma_{001}(\text { concrete services })+\gamma_{002}(\text { advocacy }) \\
& +\gamma_{003}(\text { counseling })+\gamma_{004}(\text { Chicago })+u_{0} \\
\beta_{50}= & \gamma_{500}+\gamma_{501}(\text { counseling })+\gamma_{502}(\text { Chicago })
\end{aligned}
$$

The conditional model of compliance is:

level 1:

$$
\begin{aligned}
\text { compliance }= & \pi_{0}+\pi_{1}(\text { substance abuse })+\pi_{2}(\text { parental mental } \\
& \text { health problems })+\pi_{3}(\text { housing problems }) \\
& +\pi_{4}(\text { child-care skill deficits })+\pi_{5}(\text { teenage } \\
& \text { caregiver })+\pi_{6}(\text { caregiver race })+\pi_{7}(\text { chronic } \\
& \text { neglect })+\pi_{8}(\text { prior court involvement }) \\
& +\pi_{9}(\text { extended family influence })+e
\end{aligned}
$$

level 2:

level 3:

$$
\begin{aligned}
\pi_{0}= & \beta_{00}+\beta_{01}(\text { child welfare experience }) \\
& \left.+\beta_{02} \text { (supervision adequacy }\right)+\beta_{03}(\text { job clarity }) \\
& +\beta_{04} \text { (autonomy) }+\beta_{05}(\text { deficit orientation }) \\
& \left.+\beta_{06} \text { (burnout }\right)+r_{0} \\
\pi_{1}= & \beta_{10} \\
\pi_{5}= & \beta_{50}+\beta_{51} \text { (child welfare experience) } \\
\pi_{6}= & \beta_{60} \\
\pi_{7}= & \beta_{70}+\beta_{71}(\text { supervision adequacy })+\beta_{72}(\text { job clarity }) \\
& +\beta_{73}(\text { burnout }) \\
\pi_{8}= & \left.\beta_{80}+\beta_{81} \text { (deficit orientation }\right) \\
\pi_{9}= & \left.\beta_{90}+\beta_{91} \text { (deficit orientation }\right)
\end{aligned}
$$

$$
\begin{aligned}
\beta_{00}= & \gamma_{000}+\gamma_{001}(\text { caseload size })+\gamma_{002}(\text { service intensity }) \\
& +\gamma_{003}(\text { concrete services })+\gamma_{004}(\text { advocacy }) \\
& +\gamma_{005}(\text { counseling })+\gamma_{006}(\text { Chicago })+u_{0} \\
\beta_{02}= & \gamma_{020}+\gamma_{021}(\text { Chicago }) \\
\beta_{04}= & \gamma_{040}+\gamma_{041}(\text { service intensity }) \\
\beta_{10}= & \gamma_{100}+\gamma_{101}(\text { caseload size }) \\
\beta_{60}= & \gamma_{600}+\gamma_{601}(\text { concrete services }) \\
\beta_{90}= & \gamma_{900}+\gamma_{901}(\text { counseling })+\gamma_{902}(\text { Chicago })
\end{aligned}
$$

\section{Results}

We present summaries of hierarchical linear models of collaboration and compliance in table 4 . The fully unconditional models show the proportion of variance in the criterion variables that can be attributed to each level (there are no predictor variables in these models). Workers and programs account for small but statistically significant proportions of the variance in both participation scales. On collaboration, 83 percent of the variance is between cases (within workers), 13 percent between 


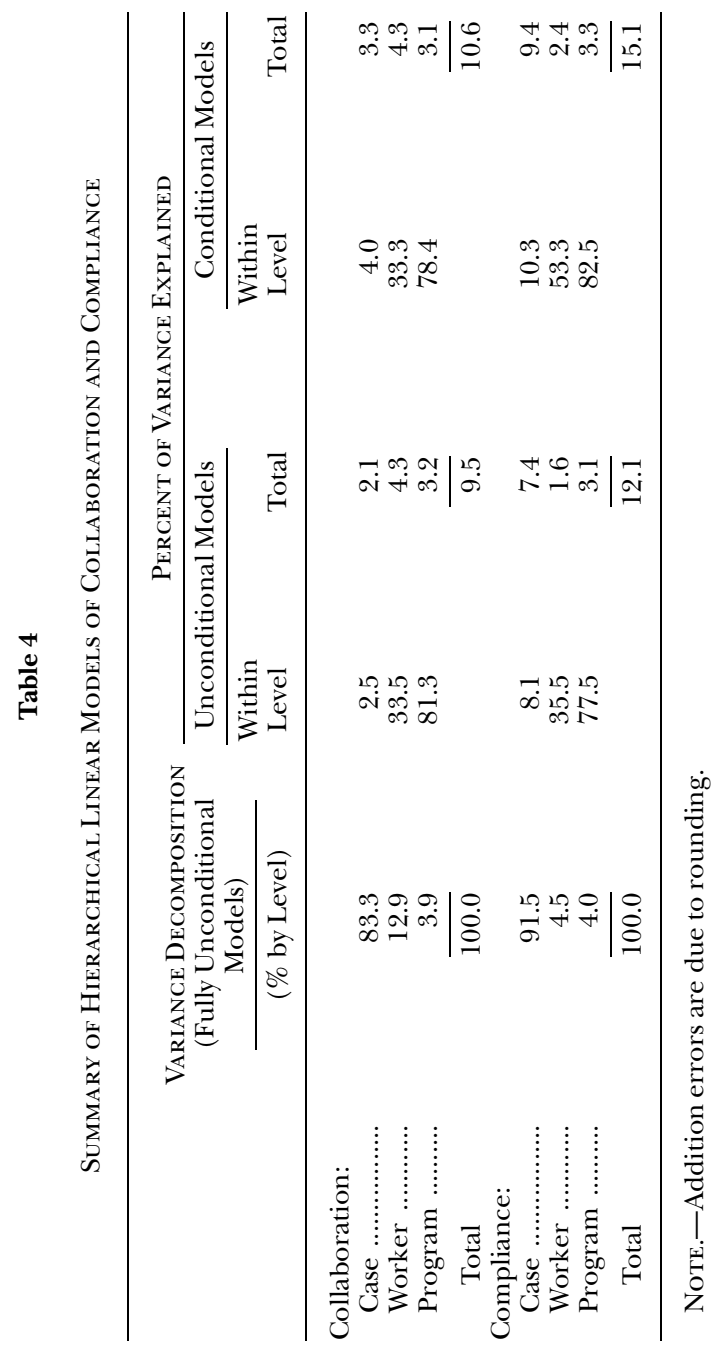


workers (within programs), and 4 percent between programs. On compliance, 92 percent of the variance is at the case level, 5 percent at the worker level, and 4 percent at the program level. It appears that workers make distinctions between cases, particularly on compliance measures, rather than responding in uniform ways across cases.

The unconditional models yield estimates of the proportion of the variance that is explained by the direct effects of predictor variables at each level. (In these models, means are treated as outcomes.) Case-level predictors account for 2 percent of the total variation in collaboration and 8 percent in compliance. Roughly one-third of the variance at the worker level is accounted for by the predictor variables at this level; this amounts to 4 percent of the total variance in collaboration and 2 percent in compliance. More than three-quarters of the variance at the program level is explained; this is 3 percent of the total variance in collaboration and compliance.

The addition of cross-level interactions (slopes as outcomes) in conditional models increases the proportion of variance explained at the case level. For compliance, slight increases are also found at higher levels. Overall, worker variables account for the largest proportion of explained variance in collaboration (4 percent), while case-level variables account for most of the explained variance in compliance (9 percent). Cross-level interactions account for 1 percent of the total variance in collaboration and 3 percent in compliance. The predictive power of these models is very modest; at best, they account for 11 percent of the variance in collaboration and 15 percent in compliance. Findings from the conditional models are described below.

\section{Collaboration}

Results of the three-level, conditional model of collaboration are shown in table 5. The intercept $\left(\gamma_{000}\right)$ is not significantly different from zero, since the grand mean of the collaboration scale (expressed in $z$-scores) is zero. The coefficients (slopes) in table 5 indicate the direction of relationships between variables.

Case-level predictors.-As expected, FPS workers report lower levels of collaboration in cases with substance abuse problems, parental mental health problems, and severe child-care skill deficits. Holding these variables constant, we find lower levels of collaboration with AfricanAmerican caregivers than others. The positive influence of extended family members is related to greater collaboration.

Worker effects.-Regardless of the race of the parent or caregiver, African-American caseworkers report higher levels of collaboration than other workers. Workers' perceptions of the adequacy of their supervision and job clarity are associated with greater collaboration, while a strong deficit orientation and worker burnout are predictive of lower levels of 
Table 5

Three-Level Conditional Model of Collaboration

\begin{tabular}{|c|c|c|c|c|c|}
\hline Fixed Effect & $\begin{array}{c}\text { Coeffi- } \\
\text { cient }\end{array}$ & SE & $T$-ratio & $p$-value & \\
\hline Intercept .. & .022 & .030 & .750 & .456 & \\
\hline \multicolumn{6}{|l|}{ Level 1 predictors: } \\
\hline Substance abuse & -.156 & .041 & -3.779 & $<.001$ & \\
\hline Parental mental health problems ............... & -.088 & .041 & -2.153 & .031 & \\
\hline Child-care skill deficits ..................................... & -.119 & .041 & -2.907 & .004 & \\
\hline African-American primary caregiver .......... & -.165 & .049 & -3.374 & .001 & \\
\hline 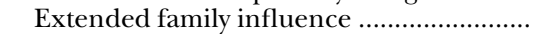 & .140 & .026 & 5.307 & $<.001$ & \\
\hline \multicolumn{6}{|l|}{ Level 2 predictors: } \\
\hline \multicolumn{6}{|l|}{ Model for worker mean $\left(\pi_{0}\right)$ : } \\
\hline 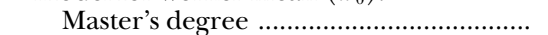 & -.057 & .064 & -.886 & .376 & \\
\hline Child welfare experience ............................ & .037 & .059 & .632 & .527 & \\
\hline African-American caseworker ................... & .185 & .074 & 2.484 & .013 & \\
\hline Supervision adequacy …….......................... & .155 & .049 & 3.159 & .002 & \\
\hline 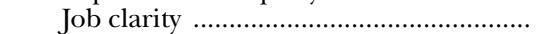 & .142 & .058 & 2.440 & .015 & \\
\hline Deficit orientation ……................................. & -.083 & .028 & -2.918 & .004 & \\
\hline 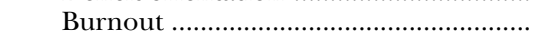 & -.072 & .030 & -2.413 & .016 & \\
\hline \multicolumn{6}{|l|}{ Slope for substance abuse $\left(\pi_{1}\right)$ : } \\
\hline 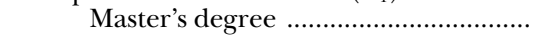 & .189 & .083 & 2.281 & .023 & \\
\hline \multicolumn{6}{|l|}{ Slope for child-care skill deficits $\left(\pi_{3}\right)$ : } \\
\hline Child welfare experience ...................... & -.172 & .081 & -2.134 & .033 & \\
\hline Slope for extended family influence $\left(\pi_{5}\right)$ : & & & & & \\
\hline Supervision adequacy ….......................... & .112 & .039 & 2.863 & .005 & \\
\hline \multicolumn{6}{|l|}{ Level 3 predictors: } \\
\hline \multicolumn{6}{|l|}{ Model for program mean $\left(\beta_{00}\right)$ : } \\
\hline Concrete services ............................................ & .081 & .029 & 2.803 & .007 & \\
\hline 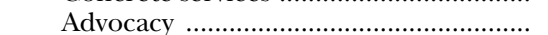 & .389 & .157 & 2.480 & .016 & \\
\hline 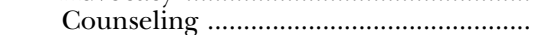 & -.086 & .126 & -.686 & .495 & \\
\hline Chicago .................................... & -.068 & .080 & -.847 & .401 & \\
\hline \multicolumn{6}{|c|}{ Slope for extended family influence $\left(\beta_{50}\right)$ : } \\
\hline \multirow{3}{*}{ 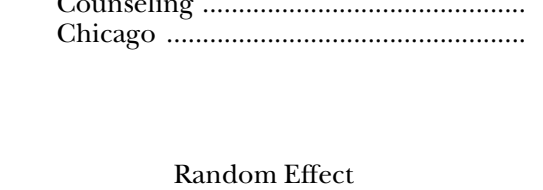 } & -.230 & .099 & -2.321 & .020 & \\
\hline & -.159 & .055 & -2.911 & .004 & \\
\hline & SD & $\begin{array}{c}\text { Variance } \\
\text { Compo- } \\
\text { nent }\end{array}$ & $\mathrm{df}$ & $\chi^{2}$ & $p$-value \\
\hline Level $1, e \ldots \ldots$. & .873 & .763 & $\ldots$ & & \\
\hline Level $2, r_{0}$. & .286 & .082 & 263 & 575.762 & $<.001$ \\
\hline Level 3, $u_{0}$ & .087 & .008 & 59 & 62.758 & .344 \\
\hline
\end{tabular}

Note. -18 iterations, 25 estimated parameters, deviance $=5,935.139$. Reliability estimates: for $\pi_{0}, 3.44$; for $\beta_{00}, .139$. Total variance explained $=.101(10.6 \%)$.

collaboration. The level 2 random effect is statistically significant, indicating that there are significant differences between workers (within programs) in mean collaboration values after the influence of the predictor variables is taken into account.

Relationships between level 2 predictors and level 1 slopes suggest that collaboration is affected by interactions between some worker and case characteristics. (1) Workers with master's degrees report significantly 
higher levels of collaboration in substance abuse cases than other workers. (2) Workers with prior child welfare experience report lower levels of collaboration in cases with severe child-care skill deficits than workers without this experience. (3) Worker perceptions of the adequacy of their supervision seem to operate in tandem with the influence of extended family members; the combination of adequate supervision for workers and positive support from extended family members is predictive of higher levels of collaboration. None of the worker variables in our analysis affect collaboration in cases with parental mental illness or those with African-American caregivers.

Program effects. - Programs that tend to provide a wide range of concrete services and advocacy efforts have relatively higher levels of collaboration. With these predictors in the model, the level 3 random effect (the amount of unexplained variance in collaboration between programs) is no longer statistically significant. None of the program variables are related to level 2 slopes. Only one level 1 slope is affected by program measures: the influence of extended family members is not as strong in Chicago or in programs that frequently provide individual and family counseling services.

\section{Compliance}

The conditional model for compliance (table 6) is more complex than the one for collaboration. Compliance is directly related to all nine case characteristics, and the effects of six of these are moderated by worker and program variables. In addition, there are three significant workerlevel predictors of compliance, two of them moderated by program-level variables. Finally, three program characteristics are directly related to our compliance scale.

Case-level effects. - As expected, results suggest that caregivers in families with substance abuse problems, parental mental health problems, housing problems, and child-care skill deficits are not as compliant as those without these problems. Moreover, it seems that teenage caregivers are not as compliant as older parents and that African-American caregivers are not as compliant as others. The number of prior reports of child neglect is negatively associated with compliance. But prior court involvement is associated with greater compliance, as is the influence of extended family members.

Worker-level effects.-High ratings of supervision adequacy and autonomy are related to greater compliance, while a deficit orientation predicts lower levels of compliance. With these variables in the model, the level 2 random error (the amount of unexplained variation in compliance between workers within programs) is statistically significant.

As in the previous model, we estimate the impact of level 2 predictors on level 1 slopes. Compared with other workers, those with prior experience in child welfare report greater success in gaining the compliance 
Table 6

Three-Level Conditional Model of Compliance

\begin{tabular}{|c|c|c|c|c|c|}
\hline Fixed Effect & $\begin{array}{c}\text { Coeffi- } \\
\text { cient }\end{array}$ & SE & $T$-ratio & $p$-value & \\
\hline \multirow{2}{*}{\multicolumn{6}{|c|}{ Level 1 predictors: }} \\
\hline & & & & & \\
\hline Substance abuse & -.314 & .044 & -7.181 & $<.001$ & \\
\hline Parental mental health problems .............. & -.177 & .041 & -4.290 & $<.001$ & \\
\hline 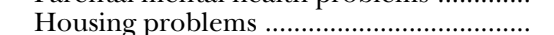 & -.160 & .045 & -3.541 & .001 & \\
\hline Child-care skill deficits ............................ & -.167 & .042 & -4.023 & $<.001$ & \\
\hline Teenage primary caregiver ……...................... & -.143 & .067 & -2.138 & .032 & \\
\hline African-American primary caregiver .......... & -.302 & .050 & -6.082 & $<.001$ & \\
\hline 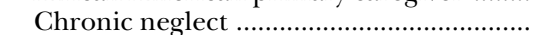 & -.089 & .023 & -3.952 & $<.001$ & \\
\hline 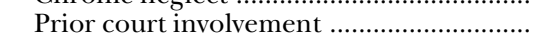 & .155 & .059 & 2.621 & .009 & \\
\hline Extended family influence ............................ & .166 & .027 & 6.120 & $<.001$ & \\
\hline \multicolumn{6}{|l|}{ Level 2 predictors: } \\
\hline \multicolumn{6}{|l|}{ Model for worker mean $\left(\pi_{0}\right)$ : } \\
\hline Child welfare experience .......................... & .047 & .051 & .911 & .363 & \\
\hline Supervision adequacy …............................ & .129 & .041 & 3.119 & .002 & \\
\hline Job clarity ……… & .028 & .050 & .566 & .578 & \\
\hline Autonomy ……………………………….... & .050 & .025 & 1.981 & .047 & \\
\hline Deficit orientation ................................. & -.056 & .023 & -2.412 & .016 & \\
\hline 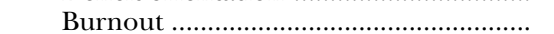 & .009 & .025 & .360 & .719 & \\
\hline \multicolumn{6}{|l|}{ Slope for teenage primary caregiver $\left(\pi_{5}\right)$ : } \\
\hline \multirow{2}{*}{\multicolumn{6}{|c|}{ Slope for chronic neglect $\left(\pi_{7}\right)$ : }} \\
\hline & & & & & \\
\hline 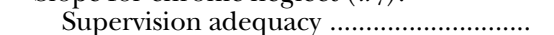 & .082 & .036 & 2.264 & .024 & \\
\hline 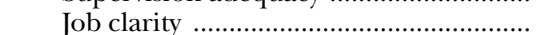 & -.146 & .046 & -3.196 & .002 & \\
\hline Burnout …… - . - & -.051 & .023 & -2.217 & .027 & \\
\hline Slope for prior court involvement $\left(\pi_{8}\right)$ : & & & & & \\
\hline Deficit orientation .. & .129 & .060 & 2.152 & .031 & \\
\hline Slope for extended family influence $\left(\pi_{9}\right)$ : & & & & & \\
\hline Deficit orientation & -.062 & .024 & -2.542 & .011 & \\
\hline \multicolumn{6}{|l|}{ Level 3 predictors: } \\
\hline \multicolumn{6}{|l|}{ Model for program mean $\left(\beta_{00}\right)$ : } \\
\hline 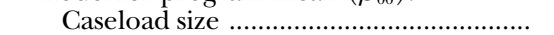 & -.059 & .019 & -3.094 & .003 & \\
\hline Service intensity . & .052 & .080 & .656 & .515 & \\
\hline Concrete services ................................. & -.024 & .028 & -.876 & .385 & \\
\hline 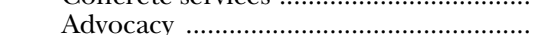 & .333 & .138 & 2.421 & .019 & \\
\hline 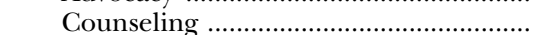 & .284 & .104 & 2.719 & .009 & \\
\hline 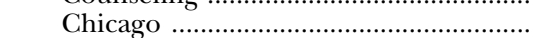 & -.018 & .062 & -.293 & .771 & \\
\hline \multicolumn{6}{|l|}{ Slope for supervision adequacy $\left(\beta_{02}\right)$ : } \\
\hline \multirow{2}{*}{\multicolumn{6}{|c|}{$\begin{array}{l}\text { Chicago ......................... } \\
\text { Slope for autonomy }\left(\beta_{04}\right) \text { : }\end{array}$}} \\
\hline & & & & & \\
\hline Service intensity ........... & .106 & .052 & 2.029 & .042 & \\
\hline Slope for substance abuse $\left(\beta_{10}\right)$ : & & & & & \\
\hline Caseload size ............................. & -.086 & .029 & -2.953 & .004 & \\
\hline \multicolumn{6}{|c|}{ Slope for African-American primary care- } \\
\hline & .101 & .038 & 2.639 & .009 & \\
\hline \multicolumn{6}{|l|}{$\begin{array}{l}\text { Concrete services ................................. } \\
\text { Slope for extended family influence }\left(\beta_{90}\right) \text { : }\end{array}$} \\
\hline 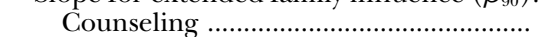 & -.225 & .101 & -2.235 & .025 & \\
\hline 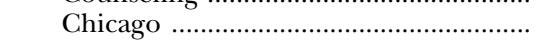 & -.133 & .056 & -2.392 & .017 & \\
\hline Random Effect & SD & $\begin{array}{c}\text { Variance } \\
\text { Compo- } \\
\text { nent }\end{array}$ & $\mathrm{df}$ & $\chi^{2}$ & $p$-value \\
\hline $1, \epsilon$ & .905 & .819 & . & . & \\
\hline 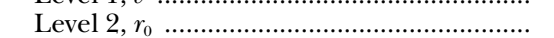 & .146 & .021 & 264 & 390.343 & $<.001$ \\
\hline Level $3, u_{0}$. & .086 & .007 & 57 & 80.124 & .023 \\
\hline
\end{tabular}

NotE.-Eight iterations, 37 estimated parameters, deviance $=5,991.318$. Reliability estimates: for $\pi_{0}, .135$; for $\beta_{00}, .185$. Total variance explained $=.151(15.1 \%)$. 
of teenage caregivers. Workers who feel adequately supervised, those who report that their job responsibilities are not clear, and those who are not burned-out report relatively higher levels of compliance in chronic neglect cases. Caseworkers with a strong deficit orientation seem to obtain better compliance in cases with prior court involvement. However, a deficit orientation relates to lower levels of compliance in cases with greater support from extended family members. As before, we find no worker-level predictors of the slopes for parental mental illness or the caregiver's race.

Program-level effects.-Results suggest that programs with relatively small caseloads and those that more frequently provide advocacy and counseling services obtain higher levels of compliance. In this model, the level 3 random error is significant, meaning that there is still some unexplained variation in compliance between programs.

Looking at the influence of program variables on level 2 slopes, we find that the perceived adequacy of supervision seems particularly important in the Chicago area and that worker autonomy is especially crucial in programs that provide more intensive services to families.

Some program characteristics relate to level 1 slopes. Programs with high caseloads have lower rates of compliance in substance abuse cases. Programs that provide a wide range of concrete services seem to be more successful in gaining the compliance of African-American caregivers. As with collaboration, the positive effect of extended family support on caregiver compliance is attenuated in Chicago and in programs that more frequently provide individual and family counseling.

\section{Discussion}

We have shown that two distinct components of client participation in FPS are related to a wide range of case, worker, and program factors. These findings should be viewed with several caveats in mind. First, the study design does not support conclusions about causality. Second, the measures of participation and predictor variables in our analysis are not ideal (measures never are). Like most studies of treatment participation, our study relies almost exclusively on worker reports. Workers' views of client participation are important because they affect decision making in child welfare (Jellinek et al. 1992; Atkinson and Butler 1996; Karski 1999; Littell 1999), but there may be little concordance between worker and client views of client participation. Since most of our case-level and worker-level measures came from the same worker, some associations between predictor and criterion variables may be inflated. The worker's overall view of the case may have influenced her responses to all questions about that case; if so, measures of presenting problems and client participation are not entirely independent. For this reason, we relied on as many "objective" case characteristics as possible (e.g., parental age, 
race, number of prior neglect reports, and prior court involvement). Consistent response sets across a variety of questions about clients and working conditions would inflate associations among variables at different levels. However, there is some evidence that common method error variance alone does not account for our findings: as indicated above, caseworkers account for less than 5 percent of the variance in compliance, suggesting that each worker makes distinctions between cases (i.e., does not rate them similarly) on these measures and that a response set bias does not affect their views of individual clients. This suggests that there is some independence between level 1 and level 2 predictors. Further, low zero-order correlations among predictor variables at each level suggest that these measures are somewhat independent.

Although we think this multilevel analysis of influences on treatment participation is both novel and conceptually sound, the proportion of variance explained by the predictor variables is disappointingly low (11 percent for collaboration and 15 percent for compliance). This may be because we relied on measures gathered for other (program evaluation) purposes. Still, the hierarchical linear models capture some of the direct, indirect, and interactive influences on participation of variables at three levels.

Our findings parallel those of other researchers who found that certain presenting problems, demographic characteristics, and external supports and constraints relate to treatment participation. Problems such as substance abuse and mental illness that impair client functioning may impede treatment participation. Other problems that are difficult to treat in FPS - chronic child neglect, severe child-care skill deficits, and inadequate housing - also relate to lower levels of participation.

As in mental health services, early childbearing and minority status are predictive of lower levels of participation in FPS. But these characteristics appear to interact with worker and program variables. For example, workers with prior experience in child welfare appeared to be more effective than others in gaining the compliance of teenage caregivers. There appear to be barriers to participation for African-American clients that are not surmounted by client-worker race matching. The reluctance of many African-American caregivers to become involved in FPS programs may reflect a distrust of traditional social service and child welfare agencies. This distrust is understandable, given the overrepresentation of African-American families and children in the child welfare system. Programs that routinely provided a wide array of concrete services seemed better able to gain the compliance of African Americans, perhaps because many of these clients needed material aid. We had no reliable measures of family income or poverty status, which may have been confounded with race and teenage parenting and may be important in its own right.

Some influences on participation appear to be external to treatment: 
overall, extended family support is linked to greater collaboration and compliance, and prior court involvement predicts greater compliance in FPS.

Some workers may be more effective than others in engaging certain clients, but we find few clear patterns here. Prior child welfare experience appears to have mixed effects that are not consistent across the two participation measures (i.e., lower levels of collaboration in cases with severe child-care skill deficits and greater compliance among teenage caregivers). Caseworkers with master's degrees are more likely to collaborate with caregivers with substance abuse problems but no more successful than other workers in gaining compliance in these cases. We are reluctant to make much of these findings.

In general, workers with a strong deficit orientation report lower levels of both collaboration and compliance. Worker perceptions of the quality of their supervision are positively associated with both participation measures. Job clarity predicts higher levels of collaboration, while burnout appears to have the opposite effect. Worker autonomy is linked to better compliance. Thus, workers' views of the families they serve and of their own working conditions seem to have an overall (direct) impact on one or both measures of client participation, while workers' prior education and experience may matter only in certain kinds of cases.

Program structure and emphasis appear to have some direct effects on client participation. Programs that provide a wide array of concrete services tend to have high levels of collaboration in treatment planning but have no more compliance than other programs. We suspect that the provision of concrete services is particularly important at the beginning of FPS, because it is difficult to address complex interpersonal problems when a family's material needs are not met. But material aid alone does not appear to be sufficient in many child welfare cases. Small caseloads and an emphasis on counseling services may be important as well, since these seem to foster compliance. An emphasis on advocacy is predictive of higher levels of both collaboration and compliance. These program characteristics may mask other, underlying differences in philosophy and organizational culture, including beliefs about the nature of family problems and helping relationships, and the relative emphasis on the worker's therapeutic versus social control functions. We are surprised that our measure of organizational climate has no direct or indirect effects on treatment participation in this sample, but perhaps other measures of program climate or culture would yield different results. Overall, program-level variations in service intensity (which are substantial) are not associated with participation measures. ${ }^{7}$

As expected, some program effects are indirect, operating in tandem with worker characteristics. For instance, adequate supervision appears to be particularly important for workers in the Chicago area. Worker autonomy seems especially important in programs that provide relatively 
intensive services to families. Other program characteristics appear to mitigate the positive influence of extended family members, which is not as potent in Chicago or in FPS programs that strongly emphasize counseling.

Most of the variation in collaboration and compliance in the Illinois FPS programs can be attributed to differences between cases (holding worker and program influences constant). This does not mean that client characteristics are solely responsible for case-level variations. Rather, these variations may be due to unmeasured differences between cases in service delivery, interactions between workers and clients, and interactions between program and case characteristics. We have shown that significant cross-level interactions explain some of the case-level variations in collaboration and compliance. The nature, severity, and chronicity of parent and family problems affect participation in FPS, but if client participation is seen solely as a function of client characteristics, workers and program administrators may miss important opportunities to do whatever they can to engage clients in treatment. Client participation in treatment planning is not consistently sought by FPS workers (Rzepnicki and Budde 1991). We believe that it should be.

\section{Directions for Future Work}

We found two components of participation in FPS (collaboration and compliance), but other distinctions could be made. For example, future studies might distinguish collaboration from congruence (agreement) in treatment planning and treat compliance and cooperation as separate phenomena. Further work is needed to identify important elements of client participation in FPS and other treatment settings.

Additional work is also needed to identify other potent influences on client participation in FPS. Although we examined a wide range of predictor variables, we would like to include even more. For instance, variations in treatment participation may relate to case-level differences in service characteristics (e.g., types, amounts, and duration of services); client perceptions of the perceived relevance, demands, and efficacy of the intervention (Kazdin et al. 1997; Kazdin and Wassell 1999); the strength of the helping alliance (Dore and Alexander 1996); and the strategies workers use to engage clients and attain compliance (Hasenfeld and Weaver 1996). Workers' expectations regarding client participation and outcomes are probably influential as well.

Further investigation of the effects of organizational variables on service provision, client participation, and outcomes is warranted. Organizational ideologies are thought to shape the helping process and roles (Hasenfeld and Weaver 1996). Just as workers' beliefs guide their approaches to families, certain assumptions underlie the structure and emphasis of FPS programs; these include assumptions about the origins of 
and solutions to problems related to child maltreatment, the nature of effective helping relationships, and the types of organizational structures and supports that facilitate effective casework. There is little information on the effects of organizational ideologies on casework, client participation, and outcomes in child welfare. This topic will become increasingly important as public child welfare agencies increase their reliance on private service providers. Agency cultures that value client participation, promote respect, emphasize practical help (e.g., material aid), and provide adequate support and supervision for frontline staff may be most effective in obtaining active participation in FPS.

\section{Conclusions}

Treatment participation is a complex phenomenon that is not well understood, particularly in involuntary settings. Just as little is known about what workers actually do in many "people-changing" programs, clients' activities and responses to treatment are rarely documented in much detail. Our study makes a modest contribution to understanding the wide range of factors that may affect client participation in intensive family preservation services. We identified two distinct components of participation and several variables at the case, worker, and program levels that were helpful in explaining variations in participation. Findings support an overall view of treatment participation as a multifaceted phenomenon that is affected by client, worker, and program characteristics; by influences external to treatment (e.g., extended family members and the legal system); and by interactions among these factors.

Further work is needed to identify important components of participation in various treatment settings and to understand the meanings of participation phenomena to both clients and helpers. Multilevel models of the influences on treatment participation are particularly promising, since they can capture important interactions among client, worker, and program characteristics. We hope that more robust models of treatment participation will be developed in the future. In particular, more attention should be paid to the direct, indirect, and interactive effects of worker and program characteristics since these may be mutable and have been underinvestigated. Better understanding of the factors that affect participation in FPS and other psychosocial interventions might lead to the development of more effective strategies for engaging clients in change efforts. This could improve their presently modest chances for success.

\section{References}

Armbruster, Paula, and Theodore Fallon. 1994. "Clinical, Sociodemographic, and Systems Risk Factors for Attrition in a Children's Mental Health Clinic." American Journal of Orthopsychiatry 64 (4): 577-85. 
Atkinson, Leslie, and Stephen Butler. 1996. "Court-Ordered Assessment: Impact of Maternal Noncompliance in Child Maltreatment Cases." Child Abuse and Neglect 20 (3): 185-90.

Berry, Marianne. 1993. "The Relative Effectiveness of Family Preservation Services with Neglectful Families.” Pp. 70-98 in Advancing Family Preservation Practice, edited by E. Susan Morton and R. Kevin Grigsby. Newbury Park, Calif.: Sage.

Blackwell, Barry. 1997. "From Compliance to Alliance: A Quarter Century of Research." Pp. 1-15 in Treatment Compliance and the Therapeutic Alliance, edited by Blackwell. Amsterdam: Harwood Academic.

Bryk, Anthony S., and Stephen W. Raudenbush. 1992. Hierarchical Linear Models: Applications and Data Analysis Methods. Newbury Park, Calif.: Sage.

Budde, Stephen. 1990. "The Use of Authority in Family First." Chicago: Chapin Hall Center for Children at the University of Chicago.

$\rightarrow$ Butler, Stephen M., Nick Radia, and Michael Magnatta. 1994. "Maternal Compliance to Court-Ordered Assessment in Cases of Child Maltreatment." Child Abuse and Neglect 18 (2): 203-11.

Cherniss, Cary. 1980. Professional Burnout in Human Service Organizations. New York: Praeger.

Child Welfare League of America. 1989. Standards for Services to Strengthen and Preserve Families with Children. Washington, D.C.: Child Welfare League of America.

Cimmarusti, Rocco A. 1992. "Family Preservation Practice Based on a Multisystems Approach." Child Welfare 71 (3): 241-56.

Cingolani, Judith. 1984. "Social Conflict Perspective on Work with Involuntary Clients." Social Work 29 (5): 442-46.

Dore, Martha M., and Leslie B. Alexander. 1996. "Preserving Families at Risk of Child Abuse and Neglect: The Role of the Helping Alliance." Child Abuse and Neglect 20: 349-61.

Drake, Brett, and Gautam N. Yadama. 1996. "A Structural Equation Model of Burnout and Job Exit among Child Protective Services Workers." Social Work Research 20 (3): $179-87$.

Famularo, Richard, Robert Kinscherff, Doris Bunshaft, Gayl Spivak, and Terrence Fenton. 1989. "Parental Compliance to Court-Ordered Treatment Interventions in Cases of Child Maltreatment." Child Abuse and Neglect 13: 507-14.

Fraser, Mark W., Kristine E. Nelson, and Jeanne C. Rivard. 1997. "Effectiveness of Family Preservation Services." Social Work Research 21 (3): 138-53.

Fraser, Mark W., Peter J. Pecora, and David A. Haapala, eds. 1991. Families in Crisis: The Impact of Intensive Family Preservation Services. Hawthorne, N.Y.: de Gruyter.

Fraser, Mark W., Peter J. Pecora, and Robert E. Lewis. 1991. "The Correlates of Treatment Success and Failure for Intensive Family Preservation Services.” Pp. 181-224 in Fraser, Pecora, and Haapala, eds.

Gitterman, Alex. 1983. "Uses of Resistance: A Transactional View." Social Work 28: 127-31.

$\rightarrow$ Glisson, Charles, and Anthony Hemmelgarn. 1998. "The Effects of Organizational Climate and Interorganizational Coordination on the Quality and Outcomes of Children's Service Systems." Child Abuse and Neglect 22: 401-21.

$\rightarrow$ Halpern, Robert. 1997. "Good Practice with Multiply Vulnerable Young Families: Challenges and Principles." Children and Youth Services Review 19 (4): 253-75.

Hasenfeld, Yeheskel, and Dale Weaver. 1996. "Enforcement, Compliance, and Disputes in Welfare-to-Work Programs.” Social Service Review 70: 235-56.

$\rightarrow$ Irueste-Montes, Ana Maria, and Francisco Montes. 1988. "Court-Ordered vs. Voluntary Treatment of Abusive and Neglectful Parents." Child Abuse and Neglect 12: 33-39.

Jayaratne, Srinika, and Wayne A. Chess. 1984. "Job Satisfaction, Burnout, and Turnover: A National Study." Social Work 29: 448-53.

$\rightarrow$ Jellinek, Michael S., J. Michael Murphy, Francis Poitrast, Dorothy Quinn, Sandra J. Bishop, and Marilyn Goshko. 1992. "Serious Child Mistreatment in Massachusetts: The Course of 206 Children through the Courts." Child Abuse and Neglect 16: 179-85.

Karski, Ruth Lawrence. 1999. "Key Decisions in Child Protective Services: Report Investigation and Court Referral." Children and Youth Services Review 21 (8): 643-56.

Kazdin, Alan E., Lisa Holland, and Michael Crowley. 1997. "Family Experience of Barriers to Treatment and Premature Termination from Child Therapy." Journal of Consulting and Clinical Psychology 65: 453-63.

Kazdin, Alan E., and Gloria Wassell. 1999. "Barriers to Treatment Participation and Thera- 
peutic Change among Children Referred for Conduct Disorder." Journal of Clinical Child Psychology 28 (2): 160-72.

Kim, Hye Lan. 1993. "The Influence of Caseworkers' Orientations toward Child Maltreating Families on Casework Activities and Case Outcomes." Ph.D. diss. University of Chicago.

Kinney, Jill, David Haapala, and Charlotte Booth. 1991. Keeping Families Together: The Homebuilders Model. New York: de Gruyter.

Kirk, Stuart A., Gary F. Koeske, and Randi D. Koeske. 1993. "Changes in Health and Job Attitudes of Case Managers Providing Intensive Services." Hospital and Community Psychiatry 44 (2): 168-73.

Lipsky, Michael. 1980. Street-Level Bureaucracy: Dilemmas of the Individual in Public Services. New York: Russell Sage Foundation.

$\rightarrow$ Littell, Julia H. 1997. "Effects of the Duration, Intensity, and Breadth of Family Preservation Services: A New Analysis of Data from the Illinois Family First Experiment." Children and Youth Services Review 19: 19-41.

1999. "Client Participation and Outcomes of Intensive Family Preservation Services." Social Work Research (in press).

Littell, Julia H., and Jeanne Howard, with Stephen Budde, Cindy Chrisman, Brenda Eckhardt, and Dianne Pellowe. 1990. "The Nature of the Work with Families in Family First." Working paper. Chicago, Chapin Hall Center for Children at the University of Chicago.

Littell, Julia H., and John R. Schuerman. In press. "What Works Best for Whom? A Closer Look at Intensive Family Preservation Services." Children and Youth Services Review.

Littell, Julia H., John R. Schuerman, Tina L. Rzepnicki, Jeanne Howard, and Stephen Budde. 1993. "Shifting Objectives in Family Preservation Programs." Pp. 99-116 in Advancing Family Preservation Practice, edited by E. Susan Morton and R. Kevin Grigsby. Newbury Park, Calif.: Sage.

Maslach, Christine, and Susan Jackson. 1986. Maslach Burnout Inventory. Palo Alto, Calif.: Consulting Psychologists.

Miller, William R. 1985. "Motivation for Treatment: A Review with Special Emphasis on Alcoholism." Psychological Bulletin 98 (1): 84-107.

Moore-Kirkland, Janet. 1981. "Mobilizing Motivation: From Theory to Practice.” Pp. 27-54 in Promoting Competence in Clients: A New/Old Approach to Social Work Practice, edited by Anthony N. Maluccio. New York: Free Press.

$\rightarrow$ Moos, Rudolf H., and Melissa J. King. 1997. "Participation in Community Residential Treatment and Substance Abuse Patients' Outcomes at Discharge." Journal of Substance Abuse Treatment 14 (1): 71-80.

Murdach, Allison D. 1980. "Bargaining and Persuasion with Nonvoluntary clients." Social Work 26 (5): 458-61.

Murphy, J. Michael, Michael Jellinek, Dorothy Quinn, Gene Smith, Francis G. Poitrast, and Marilyn Goshko. 1991. "Substance Abuse and Serious Child Mistreatment: Prevalence, Risk and Outcome in a Court Sample." Child Abuse and Neglect 15 (3): 197-211.

National Evaluation of Family Preservation Services. 1995. "A Review of Family Preservation and Family Reunification Programs." Manuscript. Westat in association with James Bell Associates and the Chapin Hall Center for Children at the University of Chicago.

Nelson, Kristine E., Miriam J. Landsman, and Janet R. Hutchinson. 1986. "Family-Based Services Inventory." Iowa City, Iowa: National Resource Center on Family Based Services.

Orlinsky, David E., Klaus Grawe, and Barbara K. Parks. 1994. "Process and Outcome in Psychotherapy: Noch Einmal." Pp. 270-376 in Handbook of Psychotherapy and Behavior Change, edited by Allen E. Bergen and Sol L. Garfield. 4th ed. New York: Wiley.

Pecora, Peter J., Mark W. Fraser, and David A. Haapala. 1991. "Client Outcomes and Issues for Program Design.” Pp. 3-32 in Family Preservation Services: Research and Evaluation, edited by Kathleen Wells and David E. Biegel. Newbury Park, Calif.: Sage.

Rooney, Ronald H. 1992. Strategies for Work with Involuntary Clients. New York: Columbia University Press.

Rzepnicki, Tina L., and Stephen Budde. 1991. "Case Planning in Family First.” In Evaluation of the Illinois Family First Placement Prevention Programs: Progress Report, June 1991. Chicago: Chapin Hall Center for Children at the University of Chicago. 
Schuerman, John R., Tina L. Rzepnicki, and Julia H. Littell. 1994. Putting Families First: An Experiment in Family Preservation. Hawthorne, N.Y.: de Gruyter.

Schwartz, Ira M., Philip AuClaire, and Linda J. Harris. 1991. "Family Preservation Services as an Alternative to the Out-of-Home Placement of Adolescents: The Hennepin County Experience." Pp. 33-46 in Family Preservation Services: Research and Evaluation, edited by Kathleen Wells and David E. Biegel. Newbury Park, Calif.: Sage.

Soulé, Charles R., Kaarina Massarene, and Kathleen Abate. 1993. "Clinician-Support Worker Teams in Family Preservation: Are Two Heads Better than One?" Pp. 39-55 in Advancing Family Preservation Practice, edited by E. Susan Morton and R. Kevin Grigsby. Newbury Park, Calif.: Sage.

StataCorp. 1999. Stata Statistical Software Reference Manual: Release 6.0. College Station, Tex.: Stata Press.

Stott, Frances, and Judith S. Musick. 1994. "Supporting the Family Support Worker." Pp. 189-215 in Putting Families First: America's Family Support Movement and the Challenge of Change, edited by Sharon L. Kagan and Bernice Weissbourd. San Francisco: JosseyBass.

Um, Myung-Yong, and Dianne F. Harrison. 1998. "Role Stressors, Burnout, Mediators, and Job Satisfaction: A Stress-Strain-Outcome Model and an Empirical Test." Social Work Research 22 (2): 100-115.

Walitzer, Kimberly S., Kurt H. Dermen, and Gerard J. Connors. 1999. "Strategies for Preparing Clients for Treatment: A Review." Behavior Modification 23 (1): 129-51.

Wolfe, David, John Aragona, Keith Kaufman, and Jack Sandler. 1980. "The Importance of Adjudication in the Treatment of Child Abusers: Some Preliminary Findings." Child Abuse and Neglect 4: 127-35.

\section{Notes}

Funding for this project was provided by a faculty grant from Bryn Mawr College and by an anonymous donor. We thank Leslie B. Alexander, Jim Baumohl, Heather Girvin, Shenyang Guo, William W. Reynolds, and anonymous reviewers for helpful suggestions on earlier versions of this article.

1. For a review in psychotherapy, see David Orlinsky, Klaus Grawe, and Barbara Parks (1994); in substance abuse treatment, see Rudolf Moos and Melissa King (1997).

2. In this study, simultaneous equations were estimated with three-stage least squares to control for effects of case characteristics on collaboration, compliance, and outcomes. Reciprocal relationships between endogenous participation and outcome measures were examined.

3. For a discussion of barriers to participation in outpatient mental health settings, see Alan E. Kazdin et al. (1997).

4. Burnout has been conceptualized as having three separate components (e.g., Kirk et al. 1993; Drake and Yadama 1996), although it is often treated as a single factor (e.g., Um and Harrison 1998). In our sample, factor analysis supported the single-factor model; hence, burnout is represented by a single scale.

5. Reliability estimates for program-level means were calculated in Stata, using the Spearman-Brown prophecy formula (StataCorp 1999).

6. For an explanation of Huber corrections, see StataCorp (1999).

7. This is consistent with Julia Littell's (1997) finding that case-level variations in the intensity of FPS have little bearing on outcomes. 